\title{
Safety and Health Cost Allocation for Urban Rail Infrastructure Project: Identifying issues and importance
}

\author{
Izatul Farrita Mohd Kamar ${ }^{1}$, Asmalia Che Ahmad², Mohmad Mohd Derus ${ }^{3}$, \\ Nik Nur Khairunnisa Nik Mohd Ainul Azman 4 \\ ${ }^{1}$ Centre of Postgraduate Studies, \\ 2,3,4 Department of Quantity Surveying, \\ Faculty of Architecture, Planning and Surveying, \\ Universiti Teknologi MARA, Seri Iskandar Campus,Seri Iskandar, Perak, Malaysia \\ izatu739@perak.uitm.edu.my
}

\begin{abstract}
This paper presents the findings of a preliminary survey, which is consist of the identification of issues and importance of safety and health cost allocation. Semi-structured interviews were conducted with seven (7) construction stakeholders who are involved in urban rail infrastructure project. The transcription and interpretation from the interview findings were carried out using Atlas.tic qualitative software. The respondent views are needed to obtain safety items and related issues in developing this framework mainly for estimating the safety cost allocation.

Keywords: Safety and Health Cost; Cost Framework; Urban Rail; Infrastructure Project

eISSN 2398-4279 @ 2018. The Authors. Published for AMER ABRA CE-Bs by e-International Publishing House, Ltd., UK. This is an open access article under the CC BY-NC-ND license (http://creativecommons.org/licenses/bync-nd/4.0/). Peer-review under responsibility of AMER (Association of Malaysian Environment-Behaviour Researchers), ABRA (Association of Behavioural Researchers on Asians) and CE-Bs (Centre for EnvironmentBehaviour Studies), Faculty of Architecture, Planning \& Surveying, Universiti Teknologi MARA, Malaysia.

DOI: https://doi.org/10.21834/ajqol.v3i13.172
\end{abstract}




\subsection{Introduction}

The construction of urban rail infrastructure project is expanding all over the time to enhance and integrate the urban public transportation services; one of the National Key Result Areas, which is a priority under the Government Transformation Program. Through the rapid construction of this project, we can hear the serious injuries and damage to properties at recent of this project sites have occurred every year. This issue has also been concerned by the Institution of Engineers Malaysia (IEM) through it press statement on 1st July 2014. In view of these incidents, IEM considers that it is important to highlight the need to strictly observe strict safety procedures in construction work especially in on-going construction sites located adjacent to public access areas.

Numerous studies had attempted to explain the various losses that could be sustained by companies after the occurrence of an accident. Many researchers found that these losses may affect the implication of costs, such as delay in project implementation, impaired company image or market loss. Moreover, Feng et al. (2015) in his discussion indicated that other cost losses to victims and their families, employers, and society may be involved. Simultaneously, accidents and the corresponding damage due to productivity, property, equipment and morale can have detrimental effects on a construction company's profit and loss statement.

However, according to Feng et al. (2014) the quantification, evaluation, and identification of many of the losses incurred in an accident are difficult as they are "hidden". These "hidden" costs may be significant, and some may be particularly prominent in the construction industry. Jallon et al. (2011a) supported the same view about the "hidden" costs as being difficult to isolate, identify, evaluate and therefore quantify. These hidden costs are often hard to calculate due to several factors, such as limited safety elements in the preliminary item. In general, there are limited provisions for safety elements in the bills of quantities. Malaysia Standard Method of Measurement of Building Works (SMM 2) (2000) Clause B.12, stated that the safety, health, and welfare of the workplace would included in the pricing of the preliminary item. The provision allocated in this clause is very ambiguous and does not include specific details.

Another factor is difficulty in applying the existing models. It is not easy to apply the models used to analyse and calculate the costs of prevention in the construction industry. This is because, firstly, they are based on studies carried out in the manufacturing sector, and secondly, the use of the traditional models which are applied for analysing these costs is limited to identifying and classifying them. López-Alonso et al. (2013) believed these models should be tailored to each company according to its own circumstances. According to Jallon et al. (2011b) for Occupational Health \& Safety (OHS) stakeholders on the ground, there is the issue of the insufficiency of mathematical models and complex calculations which are needed to prove the economic benefits of the safety investment. Reliable data on compensation costs like insurance are easy to obtain, however not much information can be found related to indirect costs such as absence, productivity loss, supervision, etc. in the workplace.

Moreover, the minimal research on safety and health items for rail infrastructure project was another factor in evaluating the safety costs allocation. Some studied on safety 
performance, safety culture, safety leadership and safety compliance in the construction industry had been carried out. Other researches had been conducted to study the safety cost model in the manufacturing sector while some researchers had carried out studies related to accident costs (direct and indirect costs) which focused more on the construction stage of a project. In contrast, there are limited studies which had been conducted to investigate the safety costs allocation, which involved the pre-construction and the construction stage particularly for rail infrastructure projects. Therefore, both the direct and indirect costs of accidents need to be examined to reflect the true costs of accidents to an employer. Due to limited studies covered on the safety cost for the construction of rail infrastructure projects, this study attempts to fill the gaps. Findings from the preliminary surveys will establish the issues, problems and importance of safety and health allocation for urban rail infrastructure projects in Malaysia.

\section{Methodology}

A qualitative approach is used to identify the critical phases for safety cost allocation, issues and importance of safety and health cost allocation. Semi-structured interviews were conducted with seven (7) construction stakeholders who are involved in urban rail infrastructure project. Inputs from them are needed to establish the importance of this research. The transcription and interpretation from the interview findings are carried out using Atlas.ti@ qualitative software. To ease the semi-structured interview process, the questions were prepared in an interview form. The initial process for the semi-structured interview is short-listing the potential participants based on the stipulated respondents' criteria. Screening forms were distributed earlier via email to the potential participants. This is to obtain their demographic details that include their designation, academic background, years of working experience and current responsibility/duty.

\section{Results and Discussion}

This research describes the qualitative approach namely the semi-structured interview. The analysis is based on the quotations from the participants, which had been labelled as $\mathrm{P}=$ Participant and $\mathrm{Q}=\mathrm{Quotation}(\mathrm{P}: \mathrm{Q})$. The interview form consists of a cover page and three sections: -

(1) demographic background of the interviewee(s); and

(2) the issues and the importance of safety and health cost allocation.

\subsection{Demographic Background}

General demographic data were compiled from the participants, which include their working experience and their position at the respective organization. Table I presents the summary of the participants' demographic background. A majority of the participants, who represent 86 percent out of total participants, were male. Different types of participant's position were representing the different view of issues and importance of safety allocation. In terms of current types of the project involved, the majority of the participants $(71 \%)$ are found to be 
actively involved in rail infrastructure projects, which are MRT project, LRT 2 and LRT 3 projects in Malaysia. The expert's view regarding the issues and importance of safety cost allocation is more reliable since the majority of participants have experience in the rail infrastructure projects.

Table 1: Demographic background of interview participants

\begin{tabular}{llll}
\hline Items & Sub-items & $\begin{array}{l}\text { Frequency } \\
(\mathrm{N})\end{array}$ & $\begin{array}{l}\text { Percentage } \\
(\%)\end{array}$ \\
\hline Gender & Male & 6 & 86 \\
\multirow{2}{*}{ Respondent's Position } & Female & 1 & 14 \\
& Project Director & 1 & 14 \\
& Safety Officer & 2 & 29 \\
& Traffic Safety & 1 & 14 \\
\multirow{5}{*}{ Working Experience } & Senior Safety Manager & 1 & 14 \\
& Quantity Surveyor & 2 & 29 \\
\multirow{2}{*}{ Current Types of Project } & 3-5 years & 4 & 57 \\
Involved & 10-14 years & 1 & 14 \\
& 15 years and above & 2 & 29 \\
& Infrastructure project (infra pipe jacking) & 2 & 29 \\
\multirow{5}{*}{ Company } & Infrastructure project (rail infrastructure-MRT) & 1 & 14 \\
& Infrastructure project (rail infrastructure-LRT 2) & 3 & 43 \\
& Infrastructure project (rail infrastructure-LRT 3) & 1 & 14 \\
& Client - Project Delivery Partner & 1 & 14 \\
\hline & Contractor & 6 & 86 \\
\hline
\end{tabular}

\subsection{The issues and importance of safety and health cost allocation}

Basically, for the section of issues and importance of safety and health cost allocation, it has been divided into several issues which are:

- $\quad$ Provisions of safety items in the Bills of Quantities (BQ)/Lump Sum Contract

- $\quad$ Determination of accident cost (direct \& indirect costs) in construction project

- $\quad$ Traditional/existing safety cost model in construction project

Based on the network of relationship, as seen in Figure 1, it is revealed that the provisions of safety items are lump sum cost where it is stated in the preliminaries item in the contract document as per stated by Participant 1, in Quotation 4 (P1:Q4). This is supported by the rest of participants (P2:Q1, P3:Q4, P4:Q4, P5:Q4, P6:Q4, P7:Q4). It is also revealed that safety cost allocation provided in the $B Q$ is not enough by Participant 1, Quotation 5 (P1:Q5) and also verified by other participants in their quotations (P2:Q2, P3:Q5, P7:Q5). However, other participants said that the provisions of safety items in the $B Q$ are enough but excluding the cost incurred after the accident happened (P4:Q5, P5:Q5, P6:Q5). If the accident happened, the cost incurred will be reviewed back to look into the accident causes, whether it is from the design error or lack of safety itself (P4:Q6). In addition, Participant 7, Quotation $6(\mathrm{P7}: \mathrm{Q} 6)$ explained that the safety budget in the preliminaries item always has been reduced by the client is the common problem in Malaysia. Due to that issue, the contractor will comply and provide the safety and health items within the budget that had been reduced by the client (P7:Q7). 


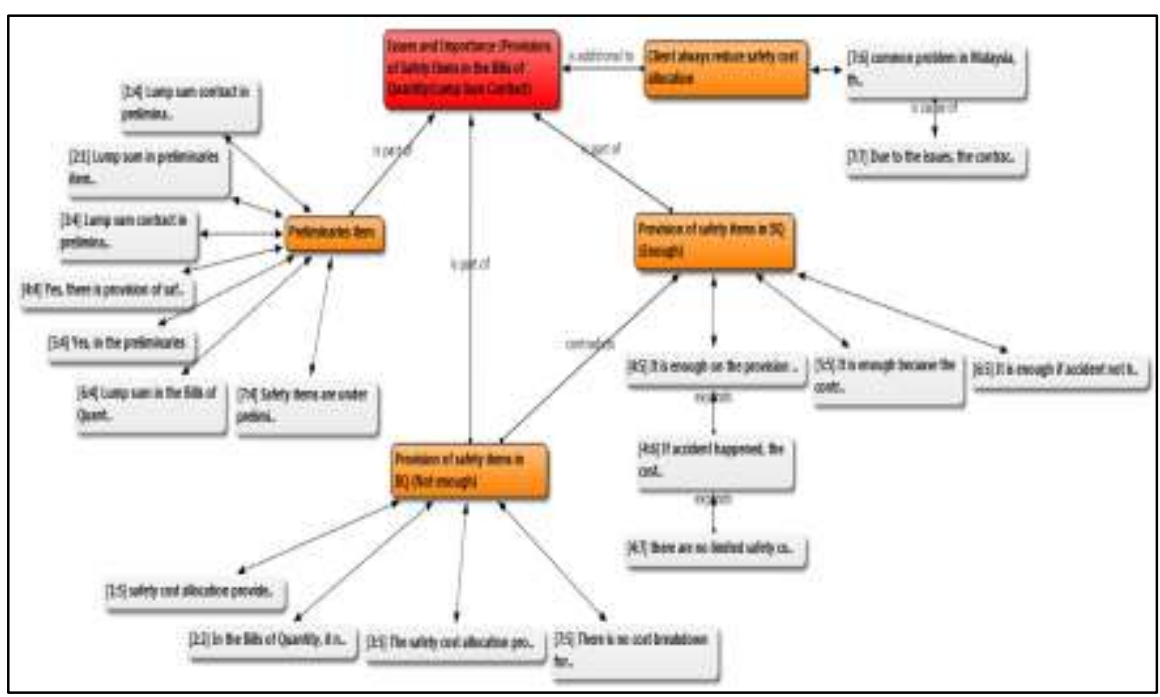

Figure 1: Provision of Safety Items is the Bills of Quantity / Lump Sum Contract

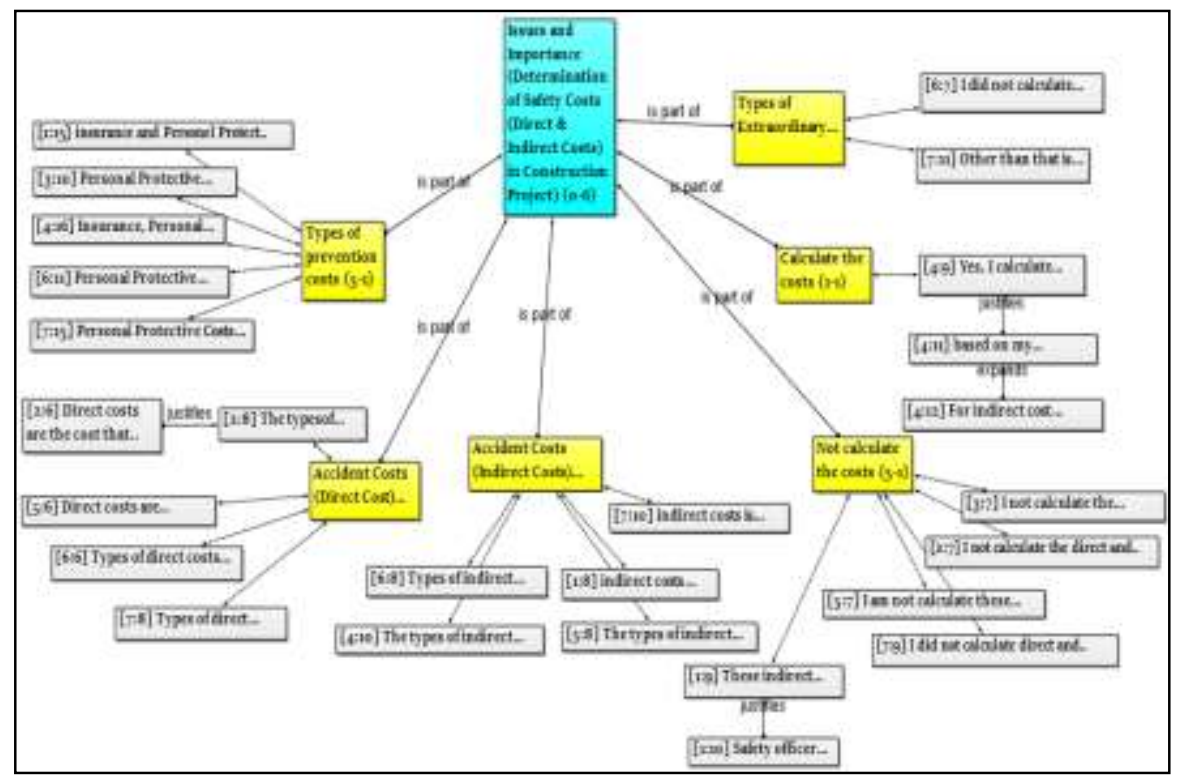

Figure 2: Determination of Safety Costs (Direct and Indirect Costs) in Construction Project For the determination of safety and health cost allocation, as seen in Figure 2, the 
participants revealed the accident cost (direct costs) are predictable costs, while accident cost (indirect costs) are the unpredictable costs that incurred the contractor after an accident happened. The participants also explained the types of prevention costs such as insurance, personal protective equipment (PPE), safety equipment's (e.g: safety harness, flagman, signage, scaffolding) and seminar or training costs (P1:Q15, P3:Q10, P4:Q16, P6:Q11, P7:Q15). The example of direct costs are such medical costs, repair costs, and production costs when stopping work order given by the authorities (P2:Q6, P5:Q6, P6:Q6, P7:Q8). While types of indirect costs are replacement of workers, recruitment with the new workers, medical cost (uninsured by insurance), cost to send back the worker's body (foreign labour), clearing costs, investigation costs and the delay of production costs due to stop work order by authority (P1:Q8, P4:Q10, P5:Q8, P6:Q8, P7:Q10). Majority of participants did not calculate the direct and indirect costs (P2:Q7, P3:Q7, P5:Q7, P6:Q7, P7:Q9) due to they are more concentrate on the authorities' requirements in construction project and cost losses incurred from the accident are hidden and difficult to quantify (P1:Q10). It is parallel with previous studies by Feng et al. (2014), Jallon et al. (2011b) and Oxenburgh and Marlow (2005) which explained the problems of safety cost allocation is hidden and difficult to quantify, evaluate and identify by the contractor. Commonly, the costs were calculated by the accounting department with project director of the company (P1:Q9). Only Participant 4, Quotation 9 was calculated the direct and indirect costs (P4:Q9). Based on his experience, the safety cost estimation is around $2.5 \%$ of the total project cost (P4:Q11). While for the accident costs estimation is about $10 \%$ of the total safety cost allocation, which is under contingencies item (P4:Q12). The Participant 6 \& 7 explained the other cost that always occurred for rail infrastructure project is extraordinary costs, which are the flood that effect to the house damage near the construction site and flat tire of public vehicles due to the road they used near the construction site (P6:Q7, P7:Q11).

The last issue for the safety cost allocation is traditional/existing safety cost model in a construction project. Majority of the participants did not use any safety cost model and for costing those safety elements (P1:Q12, P2:Q10, P3:Q9, P4:Q14) because they did not quantify or calculate the direct and indirect costs for the construction project $(\mathrm{P} 1: \mathrm{Q} 11, \mathrm{P} 2 \mathrm{Q}$ 9, P3:Q8, P5:Q9, P6:Q9). However, Participant 4, Quotation 13 (P4:Q13) had calculated the safety and health costs items by using Microsoft Excel as safety estimation method. While other participants did not know about Occupational Safety and Health (OSH) Calculator provided by Department of Occupational Safety \& Health (DOSH), which is the first safety cost model in Malaysia (P5:Q10, P6:Q10, P7:Q14). In contrast, Participant 7 in his Quotation $12(P 7: Q 12)$ revealed that when the accident happened, the contractor did not calculate the cost because if for man life, people are not considered and calculate the cost. They go to the insurance claim (P7:Q13). This problem also has been highlighted by the KLIA_JKKP (2013), that another common downside with our project practice is the tendency for clients, consultants, and contractors to ignore the cost of the accident without realizing the greatness of it impacts to the industry and the country because they leave the matters to the insurance company. 


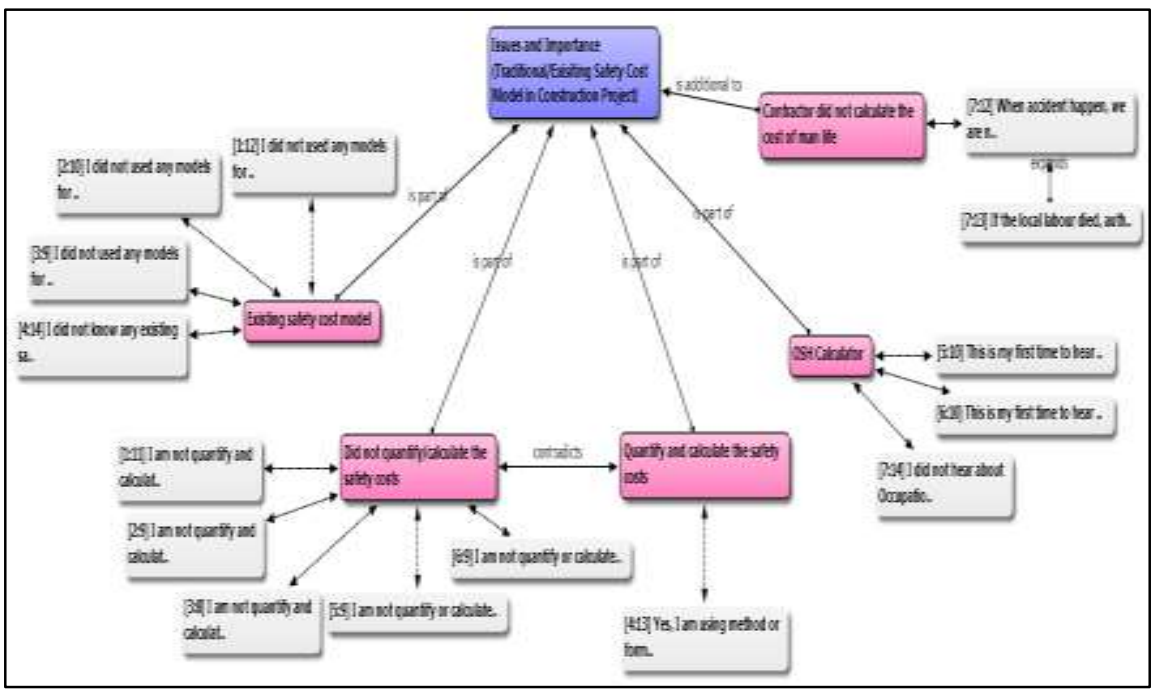

Figure 3: Traditional / Existing Safety Cost Model in Construction Project

\section{Conclusion}

The research presented in this paper is initially and part of an ongoing $\mathrm{PhD}$ research at the Faculty of Architecture, Planning and Surveying, UiTM. This paper presents the findings of a preliminary survey, which is consist of the identification of issues and the importance of safety and health cost allocation. The above findings explore the issues and importance of safety cost allocation in the construction project that needed in developing this framework mainly for estimating the safety cost allocation. These would assist to determine the actual cost of workplace accidents to make better decision-making on safety and health allowance during pre-contract stages. This framework will later encourage the clients as well as the contractors to ensure safety budget are available for the projects to complete securely and successfully.

\section{Acknowledgement}

The authors gratefully acknowledge the Centre of Postgraduate Studies, Universiti Teknologi MARA, Seri Iskandar Campus, Seri Iskandar to support this research study. The research study described in this paper is also supported by Fundamental Research Grant Scheme (FRGS) under the Malaysian Ministry of Higher Education (MOHE). Project code: FRGS/1/2016/SSI11/UITM/03/1. Special gratitude is also given to those industrial practitioners for their kind cooperation and generous contributions to the development of this research. 


\section{References}

Feng, Y., Teo, E. A. L., Ling, F. Y. Y., \& Low, S. P. (2014). Exploring the interactive effects of safety investments, safety culture and project hazard on safety performance: An empirical analysis. International Journal of Project Management, 32, 932-943. http://doi.org/10.1016/j.jproman.2013.10.016

Feng, Y., Zhang, S., \& Wu, P. (2015). Factors influencing workplace accident costs of building projects. Safety Science, 72, 97-104. http://doi.org/10.1016/j.ssci.2014.08.008

Jallon, R., Imbeau, D., \& De Marcellis-Warin, N. (2011a). A process mapping model for calculating indirect costs of workplace accidents. Journal of Safety Research, 42, 333-344. http://doi.org/10.1016/j.jsr.2011.06.008

Jallon, R., Imbeau, D., \& De Marcellis-Warin, N. (2011b). Development of an indirect-cost calculation model suitable for workplace use. Journal of Safety Research, 42, 149-164. http://doi.org/10.1016/j.jsr.2011.05.006.

KLIACS_JKKP. (2013). Kajian Mengenai Kos Kemalangan Di Tempat Kerja Bagi Sektor Pembinaan, 1-77.

López-Alonso, M., Ibarrondo-Dávila, M. P., Rubio-Gámez, M. C., \& Munoz, T. G. (2013). The impact of health and safety investment on construction company costs. Safety Science, 60, 151-159. http://doi.org/10.1016/j.ssci.2013.06.013

Oxenburgh, M., \& Marlow, P. (2005). The Productivity Assessment Tool: Computer-based cost benefit analysis model for the economic assessment of occupational health and safety interventions in the workplace. Journal of Safety Research, 36, 209-214. http://doi.org/10.1016/j.jsr.2005.06.002 